\title{
Melanoma treatment in review
}

This article was published in the following Dove Press journal:

ImmunoTargets and Therapy

\author{
Beatriz Domingues ${ }^{1-3}$ \\ José Manuel Lopes 1,2,4,5 \\ Paula Soares ${ }^{1,2,5}$ \\ Helena Pópulo1,2 \\ 'Institute of Molecular Pathology \\ and Immunology, University of \\ Porto (IPATIMUP), Porto, Portugal; \\ ${ }^{2}$ Instituto de Investigação e Inovação \\ em Saúde, Universidade do Porto, \\ Porto, Portugal; ${ }^{3}$ Faculty of Sciences, \\ University of Porto, Porto, Portugal; \\ ${ }^{4}$ Department of Pathology, Hospital S \\ João, Porto, Portugal; ${ }^{5}$ Department of \\ Pathology, Medical Faculty, University \\ of Porto, Porto, Portugal
}

\begin{abstract}
Melanoma represents the most aggressive and the deadliest form of skin cancer. Current therapeutic approaches include surgical resection, chemotherapy, photodynamic therapy, immunotherapy, biochemotherapy, and targeted therapy. The therapeutic strategy can include single agents or combined therapies, depending on the patient's health, stage, and location of the tumor. The efficiency of these treatments can be decreased due to the development of diverse resistance mechanisms. New therapeutic targets have emerged from studies of the genetic profile of melanocytes and from the identification of molecular factors involved in the pathogenesis of the malignant transformation. In this review, we aim to survey therapies approved and under evaluation for melanoma treatment and relevant research on the molecular mechanisms underlying melanomagenesis.
\end{abstract}

Keywords: cancer, melanoma, therapy, targets

\section{Introduction}

Melanoma arises from the occurrence of genetic mutations in melanocytes, the pigment producing cells, which can be found in the skin, eye, inner ear, and leptomeninges..$^{1-4}$ Although melanoma accounts for about $1 \%$ of all skin malignant tumors, cutaneous malignant melanoma represents the most aggressive and the deadliest form of skin cancer. ${ }^{5}$ This disease affects mostly the Caucasian population of both genders, ${ }^{6}$ and once it becomes metastatic, the prognosis is very poor. ${ }^{7,8}$ Therefore, early identification of this cancer is crucial for the success of patient treatment. The European Society for Medical Oncology clinical practice guidelines for cutaneous melanoma highlight the importance of a detailed diagnosis for the establishment of the tumor stage and, in some tumors, a mutation test is also required. ${ }^{9}$ Over the past years, several therapies have been approved by the US Food and Drug Administration (FDA) (Figure 1). Depending on the features of the tumor (location, stage, and genetic profile), the therapeutic options may be surgical resection, chemotherapy, radiotherapy, photodynamic therapy (PDT), immunotherapy, or targeted therapy. For patients with stage I-IIIB melanoma, surgery is the primary treatment. ${ }^{10-12}$ The surgery procedures differ according to the clinic-pathologic features of the tumor. Excision includes safety margins of $0.5 \mathrm{~cm}$ for in situ melanomas, $1 \mathrm{~cm}$ for tumors with a thickness of up to $2 \mathrm{~mm}$, and $2 \mathrm{~cm}$ for tumors thicker than $2 \mathrm{~mm} .{ }^{11}$ To improve survival, adjuvant therapies, such as targeted therapy and immunotherapy, are recommended. ${ }^{11,13}$ For patients with a solitary melanoma metastasis, metastasectomy is part of the standard of care and, in some
Correspondence: Helena Pópulo Institute of Molecular Pathology and Immunology, University of Porto (IPATIMUP), Rua Júlio Amaral de Carvalho 45, 4200-I 35 Porto, Portugal Tel +35I 225570700

Fax +35I 225570799

Email hpopulo@ipatimup.pt 


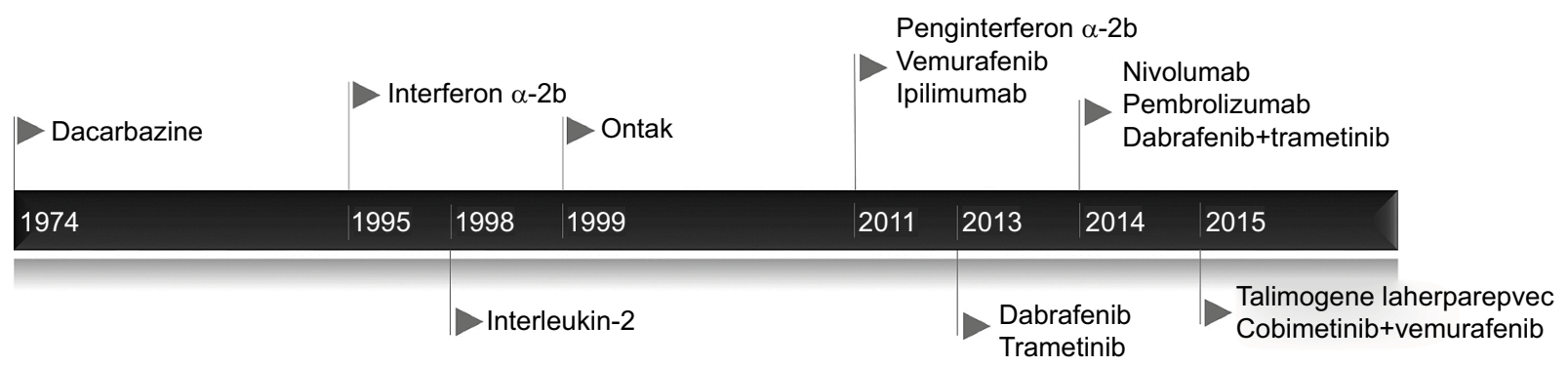

Figure I FDA-approved drugs for melanoma treatment. Dacarbazine was the first drug approved, in 1974, followed by interferon $\alpha-2 b$, interleukin-2, and ontak in the 1990s. Between 20II and 20I5, 10 therapies were approved, including selective inhibitors, antibodies, and combined targeted therapies.

Abbreviation: FDA, US Food and Drug Administration.

metastatic melanoma cases, chemotherapy treatment may also be considered. ${ }^{12,13}$ Despite being rarely indicated for primary tumor treatment, radiotherapy can be useful for the treatment of skin, bone, and brain metastases. ${ }^{14}$

Two types of limitations are relevant in melanoma therapy: 1) adverse events (AEs), which can lead to skin and gastrointestinal toxicity, can be high and usually related to immune reactions and lack of specificity for tumor cells ${ }^{15-17}$ and 2) reduced efficiency, which can occur due to resistance to immune, chemo/targeted and intralesional therapies. ${ }^{13}$ Recently, new therapeutic targets have emerged from studies of the genetic profile of melanocytes and from the identification of molecular factors involved in the pathogenesis of the malignant transformation of the melanocytic cells. ${ }^{1,18}$ In this review, we will present melanoma therapies, approved and under evaluation, which resulted from the studies of melanocyte biology and malignant transformation.

\section{Chemotherapy}

Chemotherapy was the earliest treatment option for advanced melanoma. Chemotherapy combinations have been evaluated to improve the clinical responses, but the overall survival (OS) did not show improvement. ${ }^{19}$ Resistance to apoptosis is probably the major cause of chemotherapy drug resistance in melanoma. ${ }^{20}$ Although it has been replaced by additional options, chemotherapy remains important in the palliative treatment of refractory, progressive, and relapsed melanomas. ${ }^{19}$

\section{Dacarbazine}

Dacarbazine, an alkylating agent approved in 1974 by FDA, is the standard chemotherapy medication for metastatic melanoma. Studies reported that a complete response was achieved in $<5 \%$ and 5 -year survival in $2 \%-6 \%$ of patients. ${ }^{21}$ Despite these results, dacarbazine was the standard of care because other single agents or combination chemotherapies did not reveal improvements in the OS of patients. ${ }^{21}$ Still, several clinical trials are ongoing, using only dacarbazine as comparison or in combination with other chemotherapies, immunotherapies, and targeted therapies. ${ }^{22}$

\section{Temozolomide (TMZ)}

TMZ, an oral prodrug of the active metabolite of dacarbazine, has been used in advanced melanoma. ${ }^{21}$ Compared to dacarbazine, TMZ showed a reduced improvement in median progression-free survival (PFS), but no differences were observed in OS or objective response rates. ${ }^{23}$

\section{Electrochemotherapy (ECT)}

ECT is a technique that combines the use of cytotoxic drugs, bleomycin and cisplatin, with high-intensity electric pulses, which facilitates drug delivery into the cells. ${ }^{24,25}$ ECT was reported to be effective for the treatment of cutaneous and subcutaneous nodules of melanoma. ${ }^{26,27}$ A study of the European Standard Operating Procedures of Electrochemotherapy reported an overall response of $85 \%$ and no major negative AEs were observed. ${ }^{27}$ Another remarkable aspect of ECT is that usually the treated nodules do not recur in the treated area, possibly because the treatment destroys the lymphatic stream; however, more studies are needed in this regard. ${ }^{24}$

\section{PDT}

Light-based therapy is a promising adjuvant therapy and may be a suitable palliative treatment option for patients with stage III/IV cutaneous metastatic melanomas. ${ }^{13,28}$ PDT is a minimally invasive procedure ${ }^{28-30}$ that requires a photosensitizer (PS), which is better absorbed in metabolically active tissues, and light of a defined wavelength, to activate the PS. ${ }^{13}$ Both these elements are non-toxic, but create reactive oxygen species (ROS) when combined with oxygen, through a photochemical reaction. ${ }^{30}$ ROS unleash irreversible damage to tumor cells $\mathrm{s}^{31,32}$ and tumor-associated blood 
vessels, also activating antitumor, immune, and inflammatory responses. ${ }^{33-35}$

Acai oil in nanoemulsion has been used as a novel PS in melanoma cells lines and in in vivo experimental models. The results showed $85 \%$ of melanoma cell death by late apoptosis/ necrosis, preserving high viability in normal cells. ${ }^{36}$

Although PDT can be used for the treatment of nonmalignant and malignant disease, studies reported that PDT alone has limited efficiency in melanomas. ${ }^{37,38}$ To improve PDT results in melanoma, protective mechanisms, such as pigmentation and oxidative stress resistance, have to be overcome. ${ }^{28}$ Combined therapies have been studied and, specifically, the combination of PDT and chemotherapy (dacarbazine) was reported to be an efficient treatment to reduce resistance in pigmented and unpigmented metastatic melanomas. ${ }^{39}$ Combination of PDT with immunostimulatory therapies may be more efficient in the eradication of the initial tumor and micrometastases and additionally may also decrease melanoma recurrences. ${ }^{28} \mathrm{~A}$ new clinical trial with PDT is underway in melanomas (NCT02685592).

\section{Immunotherapy}

In the 19th century, it was proposed, for the first time, that cancer and immune system are associated, and this observation was based on the frequent appearance of tumors at the sites of chronic inflammation and on the presence of immune cells in tumor tissues. ${ }^{40}$ In antitumoral responses, T-cells recognize tumor-specific antigens, becoming activated and then proliferate and differentiate, acquiring the capacity to destroy cells that express tumor-specific antigens. In addition to the stimulatory and inhibitory signaling pathways that limit T-cell antitumoral responses, cancer cells can escape T-cell detection, as usually they do not express B7 molecules. ${ }^{41}$

It is known in many types of cancer that complex interactions between the tumor and the immune system play a role in the metastatic spread to distant sites. ${ }^{42}$ Metastases are the main cause of cancer death and more accurate prognostic markers are warranted. ${ }^{42}$ Tumor infiltrating lymphocytes (TILs) have been considered in many studies as independent markers for the occurrence of lymph node metastasis. ${ }^{43}$ TILs can mediate immune responses of the host against cancer cells, being associated with a positive outcome and improved survival in patients with malignant melanomas. ${ }^{43,44}$ Based on these interactions, immunotherapy appears to be a promising treatment option for patients with advanced stage (metastatic) malignant melanomas, when compared to previous standard therapies, showing durable complete responses in selected patients with advanced melanomas. ${ }^{43,45-47}$ The immunogenic tumor microenvironment (TME), with mediators and cellular effectors of inflammation, influences the success of immunotherapies. ${ }^{45}$ The molecular pathways involved in this cancer-related inflammation are now being clarified, in order to establish new target molecules that may lead to improvements in the diagnosis and treatment of cancer. ${ }^{44}$ Despite positive results, recurrence of cancers and variable success among different cancers are not uncommon. Even in responsive cancers, the immune checkpoint inhibitor success rate is often $<50 \% .{ }^{48}$ Primary and acquired resistance to immunotherapy is common and may be due to the lack of recognition by T-cells, as described above. Also, it can involve various components of the cancer immune cycle (including regulatory T-cells [Tregs], myeloid-derived suppressor cells [MDSCs], and M2 macrophages), and interactions between multiple signaling molecules and pathways that prevent immune cell infiltration or function within the TME. ${ }^{49,50}$

In recent years, improved knowledge of the pathophysiology and a better understanding of the role of the immune system in tumor evolution have led to the development and approval of several immunotherapies (Figure 2).

\section{Interferon (IFN) $\alpha-2 b$}

IFNs are cytokines secreted by leukocytes. These signaling proteins are able to interfere with viral replication and play an important role in the immunomodulatory, antiangiogenic, antiproliferative, and antitumor activities. ${ }^{51-54}$ IFNs activate multiple cell types of the immune system, such as T-cells, B lymphocytes, natural killer cells, and dendritic cells, and inhibit other negative elements, such as Tregs and MDSCs. Beyond the known IFN effects, the complex network of different cells involved and the biologic variability of each patient influence the response to the therapy. ${ }^{51}$

IFNs offer opportunities of synergism with conventional treatments, and high-dose IFN $\alpha-2 b$ was approved by the FDA in 1995 as adjuvant therapy for the treatment of resected stage IIB/III melanoma. ${ }^{54,55}$ In melanoma, IFN- $\alpha$ demonstrates an immunomodulatory antitumor effect, inducing a stimulatory effect on major histocompatibility complex class I expression of melanoma and immune cells, being able to inhibit the proliferation of melanoma cells, with a dose-dependent proapoptotic effect. ${ }^{56} \mathrm{~A}$ recent meta-analysis reported that adjuvant IFN- $\alpha$ significantly reduces the risk of recurrence and improves survival of melanoma patients. ${ }^{57}$ However, only a minority of patients respond to IFNs and ulceration of the primary tumor is the most important predictive factor for IFN sensitivity. ${ }^{58}$ Although newer and more efficient immunotherapies have emerged in recent years, IFNs persist 


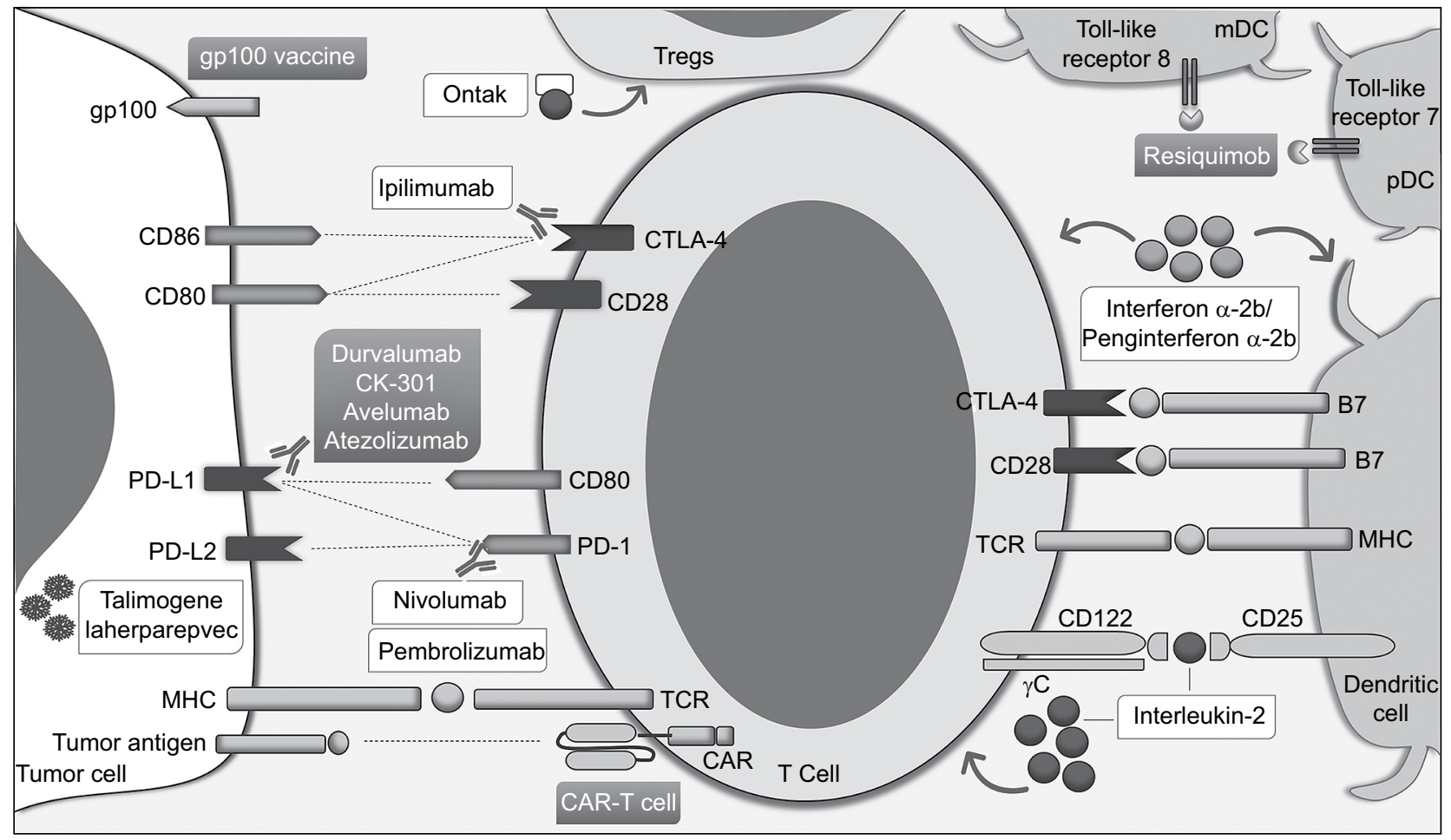

Figure 2 Immunotherapies approved by FDA (in white - interferon $\alpha$-2b/peginterferon $\alpha-2 b$, interleukin-2, ontak, ipilimumab, nivolumab, pembrolizumab, and talimogene laherparepvec) or in trials (in gray - durvalumab, CK-30I, avelumab, atezolizumab, gpI00 vaccine, resiquimod, and CAR-T cells) for cutaneous melanoma treatment. Immunotherapy induces antitumor immune responses by altering metabolites, growth factors, and cytokines, such as interferon $\alpha-2 b$ and interleukin-2, in the TME. Ipilimumab, an anti-CTLA-4 antibody, induces pro-inflammatory T-cell cytokine production, and increases clonal T-cell expansion and infiltration. The anti-PD-I antibodies, nivolumab and pembrolizumab, block the interaction between PD-I and PD-LI/PD-L2, similar to the effect of durvalumab, CK-30I, avelumab, atezolizumab, which are antiPDL-I antibodies. Other immunotherapies can activate the immune system at the TME, such as resiquimod and CAR-T cells, or suppress Tregs, as ontak. Oncolytic virus therapy with talimogene laherparepvec also interferes with the immune system, inducing melanoma cell lysis and consecutively release of tumor-specific antigens.

Abbreviations: FDA, US Food and Drug Administration; TME, tumor microenvironment; PD-I, programmed cell death protein I; PD-LI, PD-I ligand; CTLA, cytotoxic T lymphocyte-associated antigen; CAR, chimeric antigen receptor; MHC, major histocompatibility complex; TCR, T-cell receptor; Treg, regulatory T-cell; mDC, myeloid dendritic cell; pDC, plasmacytoid dendritic cell.

in clinical trials in combination with other immunotherapies and targeted therapies. ${ }^{22}$

\section{Peginterferon $\alpha-2 b$ (Peg-IFN)}

Peg-IFN was approved by the FDA (2011) as adjuvant therapy for stage III melanomas. ${ }^{59}$ Peginterferon is the combination of IFN $\alpha-2 b$ with the molecule polyethylene glycol (Peg). It was reported that this molecule allows the compound to stay longer in the blood, thus improving its therapeutic effect. ${ }^{60}$

The most common AEs observed were grade 1 liver toxicities, neutropenia, skin rash, and anemia. The only grade $3 / 4$ toxicities were lymphopenia and hyponatremia. ${ }^{61}$

\section{Interleukin-2 (IL-2)}

IL-2 is a cytokine capable of expanding effector T-cells (Teffs) and Tregs. Studies showed that high-dose IL-2 has antitumoral activity and the FDA approved (1998) this treatment for metastatic melanomas. ${ }^{62} \mathrm{~A}$ recent meta-analysis reported that the complete response rate for IL-2 treatment was $4.0 \%$, partial response $12.5 \%$, and overall response $19.7 \%$. High and intermediate dose showed no complete response differences, and thus the therapeutic dose should be reconsidered. ${ }^{63}$

Before undergoing IL-2 treatment, patients need to be evaluated, and some biomarkers have been studied, such as serum vascular endothelial growth factor (VEGF) and fibronectin levels. ${ }^{64} \mathrm{AEs}$ can include hypotension, tachycardia, peripheral edema, reversible multisystem organ failure, and cardiac arrhythmias. ${ }^{65}$ Like IFNs, IL-2 is still included in clinical trials, in combination with chemotherapy, radiotherapy, other immunotherapies, and targeted therapies. ${ }^{22}$

\section{Treg inhibition}

Tregs suppress activated Teffs and can inhibit antitumoral immune responses. ${ }^{66,67}$ In melanomas, Tregs appear in peripheral circulation and in the TME and seem to be associated with poor clinical outcome. ${ }^{68}$ The therapeutic strategy consists in the suppression of Tregs, thus increasing the antitumoral immunity. Ontak, approved by the FDA in $1999,{ }^{69}$ is the 
fusion of IL-2 protein with diphtheria toxin that selectively eliminates Tregs expressing IL-2 receptor from the peripheral blood..$^{70}$ A Phase II trial in stage IV melanoma patients showed $16.7 \%$ of partial responses, $5.0 \%$ stable disease, and $15.0 \%$ mixed responses. ${ }^{71}$ Conversely, another study reported that metastatic melanoma patients administered with ontak showed no objective clinical response, no regression of the disease, and no elimination of regulatory $\mathrm{T}$ lymphocytes. ${ }^{72}$

\section{Cytotoxic T lymphocyte-associated antigen 4 (CTLA-4) blockade}

Ipilimumab, approved by the FDA for the treatment of advanced melanomas in 2011, is an anti-CTLA-4 antibody. CTLA-4 is a inhibitory checkpoint receptor that blocks T-cell activation and induces immune tolerance. ${ }^{73,74}$ Anti-CTLA-4 antibodies act as antagonists, blocking the inhibitory effect, enhancing pro-inflammatory T-cell cytokine production, ${ }^{75}$ and increasing clonal T-cell expansion and infiltration in responding tumors. ${ }^{76}$

Combined therapies have been studied and ipilimumab with IL-2 showed similar AEs compared to the respective monotherapies, but did not show improvement in the efficacy over ipilimumab monotherapy. ${ }^{77}$ Combination of ipilimumab and Peg-IFN showed an overall response rate of $40 \%$ and median PFS of 5.9 months. ${ }^{78}$ Also, in a Phase III trial, patients with advanced melanomas were administered randomly with ipilimumab monotherapy, ipilimumab combined with gp100 peptide vaccine, or vaccine monotherapy. Ipilimumab monotherapy showed the best response rate, with a median OS of 10.1 months, followed by ipilimumab plus gp100, with a median OS of 10.0 months. These results indicate that ipilimumab is a valuable approach due to the better OS rates compared to vaccine monotherapy, which presented a median OS of 6.4 months. $^{79}$

To undergo ipilimumab treatment, melanoma patients must comply with immune-related response criteria. The AEs of this treatment include autoimmune alterations, such as dermatitis, colitis, drug-related hepatitis, endocrinopathies, and rarely neuritis, which are more frequent with high doses. ${ }^{80}$ Corticosteroids, and occasionally more intense immunosuppressive medication, may control these AEs. ${ }^{12}$ Several clinical trials are ongoing with ipilimumab in combination with chemotherapy, radiotherapy, other immunotherapies, and targeted therapies. ${ }^{22}$ Tremelimumab, another anti-CTLA-4 antibody, is also used in clinical trials in monotherapy (NCT00378482) and in combination with other immunotherapies (NCT01103635/NCT02535078/NCT02643303).

\section{Programmed cell death protein I (PD-I)/ PD-I ligand (PD-LI) blockade}

The PD-1 receptor binds to PD-L1 and PD-L2, acts as a T-cell co-inhibitory molecule, and suppresses T-cell activation. Further than being expressed on the antigen-presenting cells, ligands are also expressed in many human tumors and in cells within the TME, in response to inflammatory stimuli. Yet, the utility of PD-L1 immunostaining as a predictive biomarker for anti-PD-1 treatment remains unclear. ${ }^{81}$

Nivolumab is a high-affinity anti-PD-1 monoclonal antibody that inhibits the binding between the PD-1 receptor and its ligands PD-L1 and PD-L2 ${ }^{82}$ Nivolumab was approved (2014) by the FDA for the treatment of patients with metastatic melanoma. ${ }^{83}$ The blockade of the interaction between PD-1 and its ligands mediates immune responses and induces (preclinical) antitumor activity that reduces tumor progression. ${ }^{84}$ Nivolumab, with a PFS of 6.9 months, seems to be more efficient than monotherapies with ipilimumab, which display a median PFS of 2.9 months, or chemotherapy, with a median PFS of 2.2 months. ${ }^{84}$ The combination of nivolumab and ipilimumab achieved a median PFS of 11.5 months, superior than monotherapies, especially in patients with PD-L1 negative tumors. ${ }^{84,85}$

Pembrolizumab, an anti-PD-1 antibody, was approved by the FDA in 2015 for the treatment of advanced melanomas and may turn a new standard for the treatment of ipilimumab refractory melanomas. ${ }^{86-88}$ The antitumor activity of pembrolizumab led to a prolonged PFS and OS of patients with advanced melanomas, with less high-grade toxicity than ipilimumab. ${ }^{86}$ The combination of pembrolizumab and Peg-IFN is also well tolerated and clinically active, especially in patients with advanced melanoma that cannot be removed by surgery. ${ }^{61}$ The AEs related with this therapy are fatigue, infusion reactions, diarrhea, arthralgia, rash, nausea, pruritus, and headaches. ${ }^{12}$ More studies are needed to identify suitable prognostic biomarkers for this treatment. ${ }^{84}$

Several clinical trials are ongoing, using nivolumab and pembrolizumab in monotherapy or in combination with chemotherapy, radiotherapy, other immunotherapies, and targeted therapies. ${ }^{22}$ Other anti-PD-1 molecules are being used in trials, such as JS100 monotherapy (NCT03013101) and in combination with targeted therapies (NCT03086174), REGN2810 (NCT03002376), and PDR001 monotherapy (NCT02404441) and in combination with other immunotherapies (NCT02608268) and targeted therapies (NCT02607813/NCT02967692). 
Other anti-PD-L1 molecules are used in Phase I/ II trials, such as durvalumab in combination with other immunotherapies (NCT02535078) and targeted therapies (NCT02027961), CK-301 (NCT03212404), avelumab in combination with other immunotherapies (NCT03167177), and atezolizumab in combination with other immunotherapies (NCT03138889) and targeted therapies (NCT03178851/ NCT01656642).

\section{Oncolytic virus therapy}

FDA approved (2015) the first oncolytic virus for the treatment of melanomas, talimogene laherparepvec (T-VEC), a genetically modified herpes simplex virus type $1 .{ }^{85,89,90}$ This engineered nonpathogenic viral strain is injected directly into a metastatic melanoma nodule and while it enters into both normal and malignant cells, it only replicates in the melanoma cells, leading to tumor cell lysis and the release of tumor-specific antigens. ${ }^{89}$ These antigens are recognized by antigen-presenting cells, activating melanoma-specific T-cell responses.

Patients with refractory stage IV or unresectable stage III melanomas were treated with T-VEC and, in a Phase II clinical trial, an objective clinical response of $28 \%$ was observed. ${ }^{89}$ This strategy is safe and the AEs reported are not severe, including fatigue, chills, pyrexia, nausea, influenzalike illness, and injection site pain. ${ }^{85}$ Clinical trials are still ongoing, using T-VEC alone or in combination with chemotherapy, radiotherapy, other immunotherapies, and targeted therapies. $^{22}$

Coxsackievirus (CVA21) or CAVATAK is an oncolytic virus in late-stage clinical development that presented lytic activity against melanomas in in vitro cultures and in vivo. ${ }^{90-92}$ Ongoing clinical trials are testing CAVATAK with pembrolizumab in advanced melanomas and CAVATAK with ipilimumab in unresectable stage III-IV melanomas. ${ }^{91}$

Other oncolytic viruses are being used in trials, such as HF10 in combination with other immunotherapies (NCT03259425/NCT02272955/NCT03153085), and GLONC1 monotherapy, prior to surgery (NCT002714374).

\section{gp I00 Peptide vaccine}

gp100 is a glycoprotein expressed only by melanoma cells and, with the exception of healthy epidermal melanocytes and retina, is not expressed in healthy tissues. ${ }^{93,94}$ gp100 is recognized by cytotoxic $\mathrm{T}$ lymphocytes (CTLs), and administration of gp100 epitopes can enhance CTLs reactivity, being an appealing therapy option. Preclinical models showed that gp100 peptide monotherapy had unsatisfactory clinical benefits; therefore, it might be used as adjuvant therapy. ${ }^{93}$ Combination of gp100 peptide vaccine with IL-2 showed significant improvement in the overall clinical response and longer PFS, with a complete response of $5 \%{ }^{63}$ The median OS was longer in the combined treatment compared to IL-2 monotherapy. ${ }^{95}$ Other clinical trials are ongoing, using gp100 in monotherapy (NCT01744171/ NCT02889861) or in combination with other immunotherapies (NCT00960752/NCT00470015/NCT01176461/ NCT01176474/NCT02535078).

\section{Toll-like receptor (TLR) agonists}

TLRs are type I membrane glycoproteins that belong to the IL-1R superfamily and are able to induce the production of local cytokines, such as IFN- $\alpha$ and IL-12, that improve local immune responses. ${ }^{96}$ Moreover, TLRs may also enhance antitumor immunity. ${ }^{97}$ TLR agonists may be a potent adjuvant for vaccines and can activate the immune system in the TME. ${ }^{98}$ Resiquimod is a TLR $7 / 8$ agonist that can activate both myeloid (mDC, TLR 8) and plasmacytoid (pDC, TLR 7) dendritic cells in patients with advanced stage melanomas. ${ }^{98}$ Patients treated with resiquimod as an adjuvant therapy to the gp100 vaccination displayed upregulation of type I IFN and IFN- $\gamma$ at the peptide vaccination site, by activation of $\mathrm{pDC} / \mathrm{mDC}$, and improvement of the antitumor response with regression of in-transit melanoma metastases. ${ }^{98} \mathrm{Clinical}$ trials are ongoing, using TLR agonists in combination with chemotherapy (NCT02650635) and other immunotherapies (NCT00960752/NCT02320305).

\section{Adoptive T-cell therapy}

In adoptive cell transfer (ACT) therapy, patients are infused with a large number of melanoma-specific T-cells, but the generation of these cells is difficult and time consuming. ${ }^{99}$ The antitumoral activity of ACT is not fully understood, but may include suppression of Tregs, removal of cytokine sinks, and eradication of host tumor immunosuppressive factors. ${ }^{99}$ T-cells must be able to proliferate, to complete effector functions and to form long-lived memory T-cells that are crucial for a suitable immune response. ${ }^{100}$ In fact, in in vitro studies, the more-differentiated Teffs had enhanced antitumoral properties, but in vivo these T-cells are less effective. ${ }^{101}$ Modulation of T-cells metabolism may be a valuable method to induce the formation of memory T-cells instead of more-differentiated Teffs. Since memory T-cells exhibit a limited glucose uptake, inhibiting the glycolytic metabolism induces the formation of memory precursor cells and therefore improves antitumoral functions. ${ }^{102}$ 
In metastatic melanomas, this immunotherapy seems to be associated with complete and durable responses as well as partial responses and prolonged disease stabilization. ${ }^{103}$ ACT led to durable complete regression (24\% of the studied patients) of metastatic melanomas, with a reported median survival of $>3$ years. ${ }^{104}$ Combined therapies are efficient, and studies reported that metastasectomy in patients with progressive melanomas, undergoing ACT therapy, showed a PFS of 11 months and 5-year OS of 57\%. ${ }^{103}$ The AEs of this therapy include autoimmune alterations, such as the destruction of normal melanocytes in the eyes and skin, and immunosuppression is sometimes required to control these AEs. ${ }^{105}$ Several clinical trials are ongoing with ACT in combination with chemotherapy, radiotherapy, other immunotherapies, and targeted therapies. ${ }^{22}$

ACT with T-cells chimeric antigen receptors (CARs) is a new therapeutic approach for solid tumors, including melanomas. ${ }^{106}$ CARs comprise an extracellular domain, which is an antibody single-chain variable fragment that recognizes a specific antigen (lipid, protein, or carbohydrate antigens), a transmembrane domain, and an intracellular signaling domain, which is frequently the CD3 zeta chain of the T-cell receptor that stimulates T-cells in order to destroy the tumor cells. ${ }^{107,108}$ For this therapy, patients are infused with previously isolated T-cells that are activated and genetically modified with retroviral or plasmid vectors to generate CAR-T cells. ${ }^{107,109}$ A recent study reported that Cas9-based gene editing technique can enhance CAR-T cells efficacy. ${ }^{110}$ The selection of the target antigen must have as criterion the maximal effect in tumor cells and the minimal effect in normal cells. ${ }^{107,111}$ Although the studies in melanomas are limited, ganglioside GD2 is an example of a molecule that is highly expressed in melanoma cells and can be targeted by CARs. ${ }^{111,112}$ A Phase I trial of T-cells expressing an anti-GD2 CAR was performed in children and young adults with melanomas (NCT02107963), but no conclusive results were reported. A dose-escalation Phase I CAR-T cells trial against the antigen VEGFR2 in solid tumors, including melanomas, showed one partial response (4\%) in 24 patients. ${ }^{111}$ Nevertheless, CAR-T cells are also exposed to inhibitory immune checkpoint signals of the TME. Thus, combined therapies of CAR-T cells with a PD-1 antibody or a CTLA-4 antibody might overcome the TME features. ${ }^{107,111,113}$ Other clinical trials are ongoing, using CAR-T cells expressing cMET (NCT03060356) and CAR-T cells with anti-CD70 (NCT02830724).

\section{Biochemotherapy (BCT)}

$\mathrm{BCT}$ is the combination of chemotherapy and immunotherapy. Certain conventional chemotherapies may act in part through immune-stimulatory mechanisms. ${ }^{114}$ The most common BCT approach uses as chemotherapy a combination of dacarbazine, cisplatin (an antitumoral agent that induces DNA damage and apoptotic signals ${ }^{115}$ ), and vinblastine (a microtubule targeting agent ${ }^{116}$ ), with IL-2 and IFN $\alpha-2 b$ as immunotherapy. Compared to chemotherapy monotherapy, $\mathrm{BCT}$ showed a higher response rate and an improvement in the median PFS. However, BCT did not show improvement in OS and it was associated with severe toxicity and risk of brain metastases development. ${ }^{117}$

\section{Targeted therapy}

About $70 \%$ of patients with cutaneous melanoma harbor mutations in genes of key signaling pathways. These oncogenic mutations may be associated with melanoma cell proliferation and a malignant phenotype. ${ }^{118}$ The targeted therapy approach uses small molecule inhibitors or antibodies that affect these mutated proteins, which are important for the progression of the disease (Figure 3).

\section{BRAF inhibitors}

In the past few years, new molecular approaches have been developed to target melanoma harboring mutations. BRAF is a key serine-threonine kinase from the mitogen-activated protein kinase (MAPK) signaling pathway and $50 \%$ of cutaneous melanomas without association with chronic sun damage harbor a $B R A F$ mutation. ${ }^{119}$ Mutations in the $B R A F$ gene are associated with activation of the MAPK signaling pathway and with increased growth and proliferation of cancer cells. ${ }^{120}$ The most common BRAF mutation occurs at amino acid 600, in which the normal valine is substituted, in most cases, by glutamic acid $\left(B R A F^{V 600 E}\right)$, or, less commonly, it is substituted by lysine $\left(B R A F^{V 600 K}\right) .{ }^{12}$

Vemurafenib, a selective oral BRAF-mutant inhibitor, was approved (2011) by the FDA for the treatment of unresectable or metastatic melanomas harboring activating $B R A F^{V 600 E}$ mutations. ${ }^{121,122}$ Compared to chemotherapy, in $B R A F^{V 600 E / K}$ mutationpositive melanomas, vemurafenib improved clinical response rates, PFS, and OS of metastatic melanoma patients. Studies have reported that $90 \%$ of patients who received vemurafenib showed tumor regression. ${ }^{121}$ Several clinical trials are ongoing with vemurafenib in monotherapy and in combination with chemotherapy, immunotherapies, and other targeted therapies. ${ }^{22}$

Dabrafenib is also a selective BRAF-mutant inhibitor approved (2013) by the FDA for the treatment of unresectable or metastatic melanomas harboring $B R A F^{V 600 E}$ mutations. ${ }^{120,122}$ Several clinical trials are ongoing with dabrafenib in monotherapy and in combination with radiotherapy, immunotherapies, and other targeted therapies. ${ }^{22}$ 


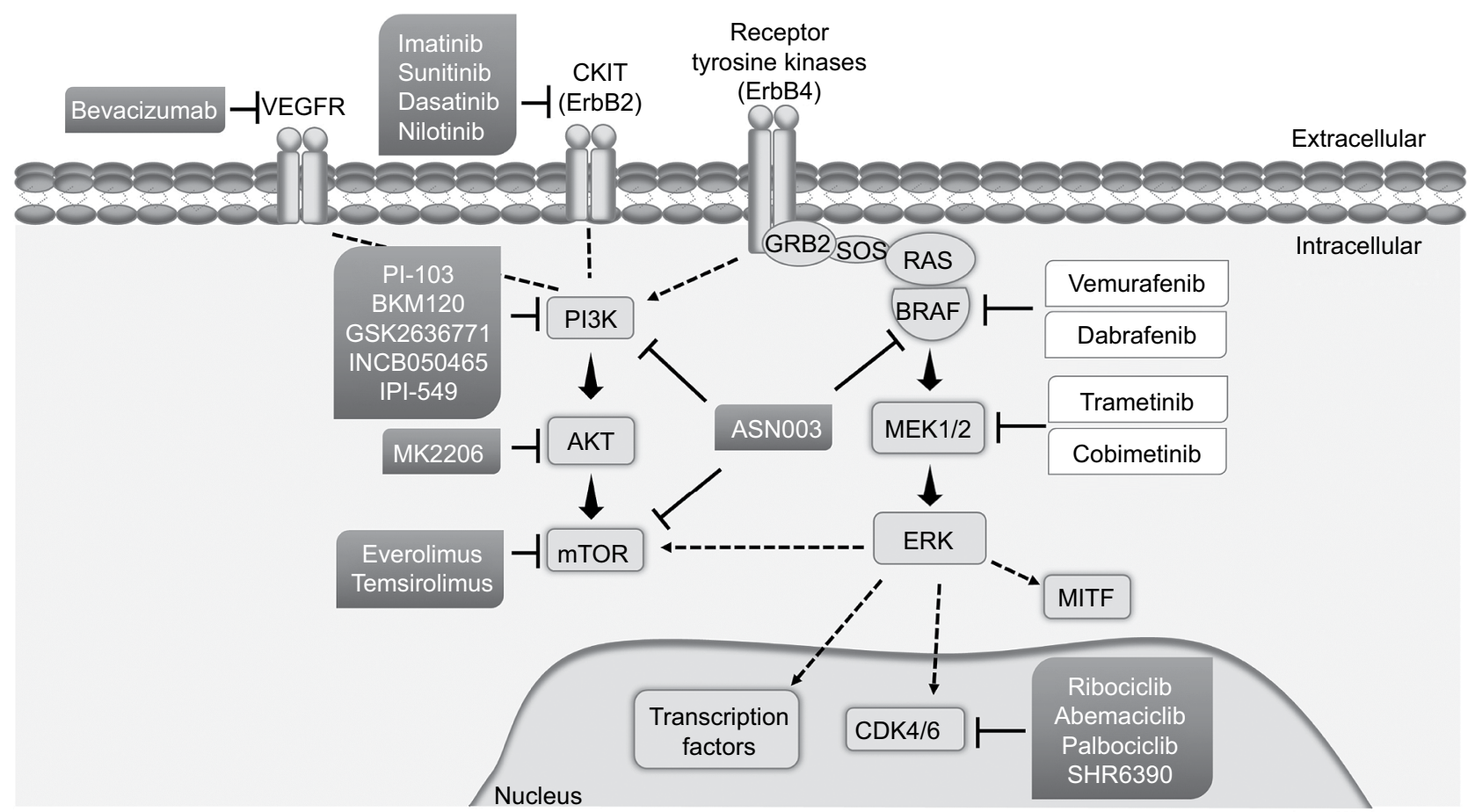

Figure 3 Targeted therapies approved by FDA (in white - vemurafenib, dabrafenib, trametinib, and cobimetinib) or in trials (in gray - imatinib, sunitinib, dasatinib, nilotinib, bevacizumab, PI-I03, BKMI20, GSK263677I, INCB050465, IPI-549, MK2206, everolimus, temsirolimus, ribociclib, abemaciclib, palbociclib, SHR6390, and ASN003) for cutaneous melanoma treatment. Mutations on key signaling oncogenes, used as targets for melanoma therapy, are associated with melanoma cell proliferation, cell-cycle progression, and malignant phenotype. Melanoma patients may benefit from combined therapies, using two different targeted therapies or targeted therapy with adjuvant immune therapy or chemotherapy.

Abbreviations: FDA, US Food and Drug Administration; mTOR, mammalian target of rapamycin; VEGFR, vascular endothelial growth factor receptor; ERK, extracellular signal-regulated kinase; MITF, microphthalmia-associated transcription factor; CDK, cyclin-dependent kinase; PI3K, phosphatidylinositol-3-OH kinase.

Encorafenib, another BRAF-mutant inhibitor, has also been used in trials in monotherapy (NCT01436656), in combination with other targeted therapies (NCT02159066/ NCT01909453) and with targeted therapies plus immunotherapies (NCT02902042/NCT03235245/NCT02631447).

Targeting the tyrosine kinases has led to remarkable response rates with better OS rates in melanoma clinical trials. ${ }^{122}$ However, the clinical benefit of these therapies is limited, due to the rapid development of multiple mechanisms of resistance, such as elevated expression of the kinases CRAF, COT1, or mutant $B R A F$, activated mutations in $N-R A S, M E K 1$, or $A K T 1$, aberrant splicing of $B R A F$, activation of phosphatidylinositol-3-OH kinase (PI3K) via the loss of phosphatase and tensin homolog (PTEN), and persistent activation of receptor tyrosine kinases. ${ }^{123}$ Combined therapies seem to be an adequate strategy for melanoma patients, in order to overcome these resistance mechanisms. ${ }^{122}$ In in vitro studies, dichloroacetate (DCA), which reverts the metabolic profile of cancer cells from glycolysis to oxidative phosphorylation, induced mammalian target of rapamycin (mTOR) inhibition and an increase of apoptosis in melanoma cells. ${ }^{124}$ Furthermore, melanoma cells resistant to vemurafenib maintained sensitivity to DCA, suggesting a possible combination therapy to overcome BRAF inhibitors resistance. ${ }^{125}$

Being a targeted therapy, it is possible to select the patients who will benefit from this treatment, based on the mutational profile of the tumor. Only patients with tumors harboring $B R A F$ mutations should undergo treatment with a BRAF inhibitor, and patients with known $R A S$-mutant should not receive this treatment. ${ }^{122,126,127}$ The AEs of this treatment appear in $90 \%$ of the patients. The duration of the treatment is dependent on the toleration to toxicity. In patients with grade 1 and tolerable grade 2 toxicities, treatment can be continued at the usual dosage, but the treatment should be suspended for higher grades. Frequent noncutaneous AEs include arthralgia, fatigue, nausea, diarrhea, and headache. Cutaneous AEs include pyrexia, rash, photosensitivity, pruritus, acneiform eruptions, erythematous hyperkeratotic follicular papules, granulomatous eruption, hyperkeratosis, warts, milia, keratoacanthoma, cutaneous squamous cell carcinoma, and basal cell carcinoma. ${ }^{122,128}$ 


\section{MEK inhibitors}

Targeting signaling effectors downstream of driver oncogenes is a valid strategy to overcome resistance to BRAF inhibitors. ${ }^{129} \mathrm{MEK}$ is a downstream target of BRAF and, in contrast to the BRAF inhibitors, MEK inhibitors showed activity in NRAS-mutant melanomas. ${ }^{130}$

Trametinib, a pharmacological MEK1/2 inhibitor with antitumoral activity, was approved (2013) as a monotherapy by the FDA for the treatment of unresectable or metastatic malignant melanomas with $B R A F$ mutations. ${ }^{122,131}$ The blocking of MEK1/2 results in the inhibition of growth factors-mediated cell signaling and decrease of tumor cells proliferation. In metastatic melanoma patients with activating $B R A F$ mutations not previously treated with selective BRAF inhibitors, trametinib was reported to improve clinical response rate, PFS, and OS, compared to chemotherapy. ${ }^{129}$ The most common general AEs of MEK inhibitors are diarrhea, peripheral edema, fatigue, nausea, and vomiting. ${ }^{122} \mathrm{~A}$ clinical trial to test the effect of trametinib in patients with $B R A F$ non-V600 mutation is ongoing (NCT02296112). Combined therapy of trametinib and dabrafenib (BRAFmutant inhibitor) showed durable objective responses in a randomized, multicenter, open-label study, ${ }^{132}$ and the combination was approved (2014) by the FDA for the treatment of unresectable and metastatic melanomas harboring $B R A F$ mutations. ${ }^{133}$ Several clinical trials are ongoing with the combination of trametinib and dabrafenib and the two drugs in combination with radiotherapy, immunotherapies, and other targeted therapies. ${ }^{22}$

In 2015, the combination of cobimetinib, an oral selective MEK inhibitor, and vemurafenib (BRAF-mutant inhibitor) was approved for the treatment of melanomas, harboring $B R A F$ mutations, which cannot be surgically removed or display metastization. ${ }^{133,134}$ This approach was reported to achieve significant improvement in the PFS of melanoma patients. ${ }^{135}$ Several clinical trials are ongoing with the combination of cobimetinib and vemurafenib and the two drugs in combination with chemotherapy, immunotherapies, and other targeted therapies. ${ }^{22}$ The most frequent AEs for the combination of BRAF and MEK inhibitors are pyrexia, chills, fatigue, nausea, vomiting, and diarrhea. ${ }^{122}$

\section{CKIT inhibitors}

In melanoma, CKIT mutations have been described in 39\% of mucosal melanoma, $36 \%$ of acral lentiginous melanoma, $28 \%$ of cutaneous melanomas arising in areas of chronic sun-damaged skin, and none in melanomas of skin without chronic sun damage. ${ }^{136,137}$ CKIT mutations or gene amplifications can lead to the constitutive ligand-independent activation of this receptor and upregulation of the MAPK and PI3K/AKT pathway. ${ }^{122,138}$ CKIT mutations have been reported across several exons and were associated with the development of drug resistance. ${ }^{139}$

Imatinib is an oral CKIT inhibitor that reveals significant activity in patients with metastatic melanoma harboring CKIT aberrations, with a response rate of $30 \%$, but with a median PFS of 3-4 months. ${ }^{140-142}$ Two clinical trials with imatinib are ongoing, in combination with chemotherapy (NCT00667953) and with immunotherapies (NCT02812693).

Other multikinase inhibitors, such as sunitinib, dasatinib, and nilotinib, may have activity in patients with melanoma harboring KIT mutations. Clinical trials with these drugs are ongoing, in combination with chemotherapy (NCT01005472) and with immunotherapies (NCT01876212). The known AEs are myelosuppression, fatigue, and fluid retention. ${ }^{122}$

\section{VEGF inhibitors}

Melanomas express high levels of VEGF, VEGF-R1, VEGF$\mathrm{R} 2$, and VEGF-R3 which are associated with poor prognosis, immune suppression, and growth of tumor neovasculature. ${ }^{143,144}$ The angiogenesis promoted by the VEGF is crucial for cancer progression. ${ }^{145}$ Therefore, VEGF blockade may be a useful approach for melanoma therapy.

Bevacizumab is an anti-VEGF monoclonal antibody that can target and neutralize VEGF and inhibit tumor growth. ${ }^{146}$ In a single-arm Phase II clinical trial, patients with previously untreated metastatic melanomas were treated with a combined therapy of TMZ and bevacizumab. ${ }^{147}$ The objective response rate was $16 \%$, the overall disease control rate was $52 \%$, the median PFS was 4.2 months, the OS was 9.6 months, and an improvement in OS in patients with $B R A F^{V 600 E}$-mutated melanoma was observed. In another single-arm Phase II clinical trial, bevacizumab was administered in combination with IFN $\alpha-2 b$. The median progressionfree rate was 4.8 months and OS rate was 17 months. These studies indicate the potential of VEGF as a target, but failed to validate this therapy for melanomas. Other clinical trials are ongoing, using bevacizumab in combination with chemotherapy (NCT03175432/NCT03175432) and with immunotherapies (NCT02681549/NCT03167177/NCT00790010/ NCT01950390/NCT02158520).

\section{PI3K-AKT-mTOR pathway inhibitors}

mTOR plays a key role in tumor development and progression, and therapies have been developed to downregulate its pathway., ${ }^{4,18}$ mTOR forms two protein complexes, mTOR 
complex 1 , which is activated by the PI3K/AKT pathway, and mTOR complex $2 .{ }^{148}$ Activation of the mTOR pathway was described in cutaneous melanoma, associated with the presence of $B R A F$ mutations and with poor prognosis. ${ }^{149}$

The combination of PI-103, a PI3K inhibitor, with the mTOR inhibitor rapamycin may effectively block the growth of melanoma cells and induce autophagy compared to both single agents separately. ${ }^{4,150}$ Studies showed that PI3K-AKT pathway inhibitors led to a higher increase of the apoptosis rates compared to BRAF or MEK inhibitors. ${ }^{151}$ Other PI3K inhibitors are being used in clinical trials, such as BKM120 in combination with other targeted therapies (NCT02159066), GSK2636771 in combination with immunotherapies (NCT03131908), INCB050465 in combination with other targeted therapies and with immunotherapies (NCT02646748), and IPI-549 monotherapy compared to the combination with immunotherapies (NCT002637531). An AKT inhibitor, MK2206, is also being used in a trial, in combination with chemotherapy (NCT01480154).

The antitumor effects of mTOR inhibition may be enhanced when combined with MAPK pathway inhibitors. An increase in mTOR pathway activation was observed in cells transfected with BRAF vectors and $B R A F$-mutated melanoma cell lines were reported to be more sensitive to mTOR inhibition. ${ }^{152}$ Moreover, inhibition of AKT or mTOR and combined inhibition of PI3K and $\mathrm{mTOR}$ were reported to be alternative strategies to overcome BRAF inhibitors resistance. ${ }^{153,154}$ A clinical trial is ongoing to test the effect of two mTOR inhibitors, everolimus or temsirolimus, in combination with a BRAF inhibitor (NCT01596140), and another trial is testing ASN003, a BRAF inhibitor with additional selective activity against $\mathrm{PI} 3 \mathrm{~K}$ and $\mathrm{mTOR}$ kinases (NCT02961283). Combination of low-dose mTOR inhibitors with immunotherapy needs clinical validation, as mTOR inhibition can result in either immunosuppression or immune activation, depending on the dose, timing, and sequencing of administration. ${ }^{155}$

\section{Cyclin-dependent kinase (CDK) inhibitors}

In familial melanomas, $2 \%$ are associated with germline mutations in $C D K 4 .{ }^{156} C D K 4$ is an oncogene that controls cellular proliferation and it is inhibited by $\mathrm{p} 16 .^{12,157-159}$ Beyond CDK4, CDK6 and cyclins (D1, D2, or D3) also control the point in G1. ${ }^{160} \mathrm{CDK} 4 /$ cyclin D kinase hyperactivation, associated with the mutation of $C D K 4$, amplification of $c y c l i n D$, or complete deletion of $p 16 I N K 4 a$, leads to an increased risk of developing melanomas. ${ }^{161}$
A new generation of selective CDK4/6 inhibitors, including ribociclib, abemaciclib, and palbociclib, has enabled tumors to be targeted with improved effectiveness and fewer AEs. ${ }^{159}$ Abemaciclib has also been reported to induce growth regression in vemurafenib-resistant melanoma models, in which high levels of cyclin D1 expression and MAPK-pathway reactivation were observed. ${ }^{162}$ The appropriate selection of patients harboring $C D K 4$ mutations seems crucial for the success of the therapy. ${ }^{159} \mathrm{CDK} 4 / 6$ inhibitors are in use in clinical trials for melanoma, such as ribociclib in combination with targeted therapies (NCT01781572/NCT02159066), abemaciclib monotherapy (NCT02308020), in combination with chemotherapy (NCT02857270) and with immunotherapies (NCT02791334), palbociclib monotherapy (NCT01037790) and in combination with targeted therapies (NCT02202200), and SHR6390 monotherapy (NCT02671513).

\section{ErbB4 inhibitor}

ErbB4 belongs to the ErbB family of tyrosine kinase receptors. ErbB4 mutations were identified in melanomas and are associated with increased kinase activity and transformation ability. Thus, the development of selective inhibitors of ErbB4 may help in the treatment of melanomas. It was reported that melanoma cells expressing mutant $E r b B 4$ which were submitted to shRNA-mediated knockdown of ErbB4 or treatment with the ErbB inhibitor lapatinib displayed reduced cell growth. ${ }^{163}$

\section{Conclusion}

The understanding of melanoma pathogenesis was crucial for the development of new therapeutic modalities. Characterization of oncogenic signaling pathways and interactions allowed the identification of novel targets for clinically effective treatments, such as pathways inhibitors and immune checkpoint antibodies. Although it represents an advancement for melanomas treatment, these types of approaches face several challenges. The comprehensive features of patients that will benefit from each strategy aim to establish biomarkers (eg, specific mutations) for the best (eg, targeted) therapy in advanced melanomas. The clinical tolerated doses are also an important issue, as it must comply with an acceptable tumor inhibition with minimal AEs. Moreover, patient and tumor heterogeneity are associated with different mechanisms of resistance, which influence negatively clinical outcomes in melanomas. To overcome these resistance mechanisms, a synergy between strategies (chemotherapy, immunotherapy, and targeted therapy) appears to be a suitable approach, targeting distinct pathways. Recently, the number of approved immunotherapies has been increasing. Favorable therapy 
results, in melanoma and in other types of cancer, can be explained by the immune response triggered that produces a T-cell repertoire, which adapts to heterogeneous tumors, and generates memory T-cells that guarantee efficient responses against recurrent tumor.

Depending on the molecular features of the patients and tumors, as well as the responses to therapy, personalized treatment should be considered for melanoma patients, in order to achieve better clinical benefits. Further research is necessary to explore oncogenic pathways and the TME potential in the treatment of melanomas.

\section{Acknowledgments}

This study was supported by the Portuguese Foundation for Science and Technology through a Post-Doc grant to HP (ref: SFRH/BPD/85249/2012). IPATIMUP integrates the i3S Research Unit, which is partially supported by FCT. This work was financed by FEDER - Fundo Europeu de Desenvolvimento Regional funds through COMPETE 2020 - Operational Programme for Competitiveness and Internationalisation (POCI), Portugal 2020, and by Portuguese funds through FCT - Fundação para a Ciência e a Tecnologia/Ministério da Ciência, Tecnologia e Inovação in the framework of the project "Institute for Research and Innovation in Health Sciences" (POCI-01-0145-FEDER-007274). Further funding was obtained from the project "Advancing cancer research: from basic knowledgment to application"; NORTE-01-0145-FEDER-000029; "Projetos Estruturados de I\&D\&I", funded by Norte 2020 - Programa Operacional Regional do Norte. This work was also funded by the European Regional Development Fund (ERDF) through the Operational Programme for Competitiveness and Internationalisation - COMPETE 2020, and Portuguese national funds via FCT - Fundação para a Ciência e a Tecnologia, under project POCI-01-0145-FEDER-016390: CANCEL STEM.

\section{Disclosure}

The authors report no conflicts of interest in this work.

\section{References}

1. Gray-Schopfer V, Wellbrock C, Marais R. Melanoma biology and new targeted therapy. Nature. 2007;445(7130):851-857.

2. Davids L, Kleemann B. The menace of melanoma: a photodynamic approach to adjunctive cancer therapy. In: Huynh Thien Duc G, editor. Melanoma - From Early Detection to Treatment. Croatia: INTECH Open Access Publisher; 2013.

3. Tolleson WH. Human melanocyte biology, toxicology, and pathology. J Environ Sci Health C Environ Carcinog Ecotoxicol Rev. 2005;23(2):105-161.

4. Pópulo H, Soares P, Lopes JM. Insights into melanoma: targeting the mTOR pathway for therapeutics. Expert Opin Ther Targets. 2012;16(7):689-705.
5. American Cancer Society. Cancer Facts \& Figures 2017; 2017. Available from: http://www.cancer.org/acs/groups/content/@editorial/ documents/document/acspc-048738.pdf. Accessed November 2017.

6. Ferlay J, Soerjomataram I, Dikshit R, et al. Cancer incidence and mortality worldwide: sources, methods and major patterns in GLOBOCAN 2012. Int J Cancer. 2015;136(5):E359-E386.

7. Jiang BP, Zhang L, Guo XL, et al. Poly(N-phenylglycine)-based nanoparticles as highly effective and targeted near-infrared photothermal therapy/photodynamic therapeutic agents for malignant melanoma. Small. 2017;13(8):1-15.

8. Bombelli FB, Webster CA, Moncrieff M, Sherwood V. The scope of nanoparticle therapies for future metastatic melanoma treatment. Lancet Oncol. 2014;15(1):e22-e32.

9. Dummer R, Hauschild A, Lindenblatt N, Pentheroudakis G, Keilholz U. Cutaneous melanoma: ESMO Clinical Practice Guidelines for diagnosis, treatment and follow-up. Ann Oncol. 2015;26(Suppl 5):v126-v132.

10. Miller KD, Siegel RL, Lin CC, et al. Cancer treatment and survivorship statistics, 2016. CA Cancer J Clin. 2016;66(4):271-289.

11. van Zeijl M, van den Eertwegh A, Haanen J, Wouters M. (Neo) adjuvant systemic therapy for melanoma. Eur J Surg Oncol. 2017;43(3):534-543.

12. Batus M, Waheed S, Ruby C, Petersen L, Bines SD, Kaufman HL. Optimal management of metastatic melanoma: current strategies and future directions. Am J Clin Dermatol. 2013;14(3):179-194.

13. Austin E, Mamalis A, Ho D, Jagdeo J. Laser and light-based therapy for cutaneous and soft-tissue metastases of malignant melanoma: a systematic review. Arch Dermatol Res. 2017;390(4):229-242.

14. Garbe C, Peris K, Hauschild A, et al. Diagnosis and treatment of melanoma. European consensus-based interdisciplinary guideline update 2016. Eur J Cancer. 2016;63:201-217.

15. Li J, Wang Y, Liang R, et al. Recent advances in targeted nanoparticles drug delivery to melanoma. Nanomedicine. 2015;11(3):769-794.

16. Sharma SK, Huang Y-Y, Hamblin MR. Melanoma resistance to photodynamic therapy. In: Rapozzi V, Jori G, editors. Resistance to Photodynamic Therapy in Cancer. New York: Springer; 2015:229-246.

17. Widakowich C, de Castro G, De Azambuja E, Dinh P, Awada A. Side effects of approved molecular targeted therapies in solid cancers. Oncologist. 2007;12(12):1443-1455.

18. Ko JM, Fisher DE. A new era: melanoma genetics and therapeutics. J Pathol. 2011;223(2):242-251.

19. Wilson MA, Schuchter LM. Chemotherapy for melanoma. Melanoma. New York: Springer; 2016:209-229.

20. Soengas MS, Lowe SW. Apoptosis and melanoma chemoresistance. Oncogene. 2003;22(20):3138-3151.

21. Kim C, Lee CW, Kovacic L, Shah A, Klasa R, Savage KJ. Long-term survival in patients with metastatic melanoma treated with DTIC or temozolomide. Oncologist. 2010;15(7):765-771.

22. ClinicalTrials.gov [database on the Internet]. Bethesda, MD: US National Library of Medicine. Available from: https://clinicaltrials. gov/. Accessed November, 2017.

23. Middleton MR, Grob J, Aaronson N, et al. Randomized phase III study of temozolomide versus dacarbazine in the treatment of patients with advanced metastatic malignant melanoma. J Clin Oncol. 2000;18(1):158-166.

24. Testori A, Ribero S, Bataille V. Diagnosis and treatment of in-transit melanoma metastases. Eur J Surg Oncol. 2017;43(3):544-560.

25. Miklavčič D, Serša G, Brecelj E, et al. Electrochemotherapy: technological advancements for efficient electroporation-based treatment of internal tumors. Med Biol Eng Comput. 2012;50(12):1213-1225.

26. Matthiessen LW, Chalmers RL, Sainsbury DCG, et al. Management of cutaneous metastases using electrochemotherapy. Acta Oncol. 2011;50(5):621-629.

27. Marty M, Sersa G, Garbay JR, et al. Electrochemotherapy: an easy, highly effective and safe treatment of cutaneous and subcutaneous metastases: results of ESOPE (European Standard Operating Procedures of Electrochemotherapy) study. Eur J Cancer Suppl. 2006;4(11):3-13. 
28. Baldea I, Filip A. Photodynamic therapy in melanoma - an update. $J$ Physiol Pharmacol. 2012;63(2):109-118.

29. Mroz P, Yaroslavsky A, Kharkwal GB, Hamblin MR. Cell death pathways in photodynamic therapy of cancer. Cancers. 2011;3(2):2516-2539.

30. Yin R, Wang M, Huang Y-Y, et al. Photodynamic therapy with decacationic [60]fullerene monoadducts: effect of a light absorbing electron-donor antenna and micellar formulation. Nanomedicine. 2014;10(4):795-808.

31. Dougherty TJ, Gomer CJ, Henderson BW, et al. Photodynamic therapy. J Natl Cancer Inst. 1998;90(12):889-905.

32. Brown SB, Brown EA, Walker I. The present and future role of photodynamic therapy in cancer treatment. Lancet Oncol. 2004;5(8):497-508.

33. Henderson BW, Dougherty TJ. How does photodynamic therapy work? Photochem Photobiol. 1992;55(1):145-157.

34. Lucky SS, Soo KC, Zhang Y. Nanoparticles in photodynamic therapy. Chem Rev. 2015;115(4):1990-2042.

35. Longo J, Muehlmann L, Almeida-Santos M, Azevedo R. Preventing metastasis by targeting lymphatic vessels with photodynamic therapy based on nanostructured photosensitizers. J Nanomed Nanotechnol. 2015;6(5):1.

36. Monge-Fuentes V, Muehlmann LA, Longo JPF, et al. Photodynamic therapy mediated by acai oil (Euterpe oleracea Martius) in nanoemulsion: a potential treatment for melanoma. J Photochem Photobiol B. 2017;166:301-310.

37. Nelson JS, McCullough JL, Berns MW. Photodynamic therapy of human malignant melanoma xenografts in athymic nude mice. $J$ Natl Cancer Inst. 1988;80(1):56-60.

38. Huang Y-Y, Vecchio D, Avci P, Yin R, Garcia-Diaz M, Hamblin MR. Melanoma resistance to photodynamic therapy: new insights. Biol Chem. 2013;394(2):239-250.

39. Biteghe FN, Davids L. A combination of photodynamic therapy and chemotherapy displays a differential cytotoxic effect on human metastatic melanoma cells. J Photochem Photobiol B. 2017;166:18-27.

40. Balkwill F, Mantovani A. Inflammation and cancer: back to Virchow? Lancet. 2001;357(9255):539-545.

41. Sharma P, Allison JP. The future of immune checkpoint therapy. Science. 2015;348(6230):56-61.

42. Jemal A, Siegel R, Ward E, Hao Y, Xu J, Thun MJ. Cancer statistics, 2009. CA Cancer J Clin. 2009;59(4):225-249.

43. Gata VA, Lisencu CI, Vlad CI, Piciu D, Irimie A, Achimas-Cadariu P. Tumor infiltrating lymphocytes as a prognostic factor in malignant melanoma. Review of the literature. J BUON. 2017;22(3):592-598.

44. Mantovani A, Allavena P, Sica A, Balkwill F. Cancer-related inflammation. Nature. 2008;454(7203):436-444.

45. Gasser S, Lim LH, Cheung FS. The role of the tumour microenvironment in immune therapy. Endocr Relat Cancer. 2017;24(12): ERC-17-0146.

46. Delitto D, Wallet SM, Hughes SJ. Targeting tumor tolerance: a new hope for pancreatic cancer therapy? Pharmacol Ther. 2016;166:9-29.

47. Schreiber RD, Old LJ, Smyth MJ. Cancer immunoediting: integrating immunity's roles in cancer suppression and promotion. Science. 2011;331(6024):1565-1570.

48. Chen DS, Mellman I. Elements of cancer immunity and the cancerimmune set point. Nature. 2017;541(7637):321-330.

49. Gide TN, Wilmott JS, Scolyer RA, Long GV. Primary and acquired resistance to immune checkpoint inhibitors in metastatic melanoma. Clin Cancer Res. 2018;24(6):1260-1270.

50. Sharma P, Hu-Lieskovan S, Wargo JA, Ribas A. Primary, adaptive, and acquired resistance to cancer immunotherapy. Cell. 2017;168(4):707-723.

51. Sanlorenzo M, Vujic I, Carnevale-Schianca F, et al. Role of interferon in melanoma: old hopes and new perspectives. Expert Opin Biol Ther. 2017;17(4):475-483

52. Lindenmann J. Induction of chick interferon: procedures of the original experiments. Methods Enzymol. 1981;78(Pt A):181-188.

53. Pestka S, Langer JA, Zoon KC, Samuel CE. Interferons and their actions. Annu Rev Biochem. 1987;56(1):727-777.
54. Rafique I, Kirkwood JM, Tarhini AA. Immune checkpoint blockade and interferon- $\alpha$ in melanoma. Semin Oncol. 2015;42(3):436-447.

55. Kirkwood JM, Ibrahim JG, Sosman JA, et al. High-dose interferon alfa$2 \mathrm{~b}$ significantly prolongs relapse-free and overall survival compared with the GM2-KLH/QS-21 vaccine in patients with resected stage IIB-III melanoma: results of intergroup trial E1694/S9512/C509801. J Clin Oncol. 2001;19(9):2370-2380.

56. Roh MR, Zheng Z, Kim HS, Jeung H-C, Rha SY, Chung KY. Difference of interferon- $\alpha$ and interferon- $\beta$ on melanoma growth and lymph node metastasis in mice. Melanoma Res. 2013;23(2):114-124.

57. Ives NJ, Suciu S, Eggermont AM, et al. Adjuvant interferon- $\alpha$ for the treatment of high-risk melanoma: an individual patient data metaanalysis. Eur J Cancer. 2017;82:171-183.

58. Eggermont AM, Suciu S, Rutkowski P, et al. Long term follow up of the EORTC 18952 trial of adjuvant therapy in resected stage IIB-III cutaneous melanoma patients comparing intermediate doses of interferon-alpha-2b (IFN) with observation: ulceration of primary is key determinant for IFN-sensitivity. Eur J Cancer. 2016;55:111-121.

59. Eggermont AM, Suciu S, Santinami M, et al. Adjuvant therapy with pegylated interferon alfa- $2 \mathrm{~b}$ versus observation alone in resected stage III melanoma: final results of EORTC 18991, a randomised phase III trial. Lancet. 2008;372(9633):117-126.

60. Harris JM, Chess RB. Effect of pegylation on pharmaceuticals. Nat Rev Drug Discov. 2003;2(3):214-221.

61. Zarour HM, Tawbi H, Tarhini AA, et al. Study of anti-PD-1 antibody pembrolizumab and pegylated-interferon alfa-2b (Peg-IFN) for advanced melanoma. J Clin Oncol. 2015;33(15_Suppl):e20018.

62. Krieg C, Létourneau S, Pantaleo G, Boyman O. Improved IL-2 immunotherapy by selective stimulation of IL-2 receptors on lymphocytes and endothelial cells. Proc Natl Acad Sci U S A. 2010;107(26): 11906-11911.

63. Bright R, Coventry BJ, Eardley-Harris N, Briggs N. Clinical response rates from interleukin-2 therapy for metastatic melanoma over 30 years' experience: a meta-analysis of 3312 patients. $J$ Immunother. 2017;40(1):21-30.

64. Sabatino M, Kim-Schulze S, Panelli MC, et al. Serum vascular endothelial growth factor and fibronectin predict clinical response to highdose interleukin-2 therapy. J Clin Oncol. 2009;27(16):2645-2652.

65. Bhatia S, Tykodi SS, Thompson JA. Treatment of metastatic melanoma: an overview. Oncology (Williston Park). 2009;23(6):488-496.

66. Han Y, Guo Q, Zhang M, Chen Z, Cao X. CD69+ CD4+ CD25- T cells, a new subset of regulatory $\mathrm{T}$ cells, suppress $\mathrm{T}$ cell proliferation through membrane-bound TGF- $\beta 1$. J Immunol. 2009;182(1):111-120.

67. de Lafaille MAC, Lafaille JJ. Natural and adaptive foxp3+ regulatory T cells: more of the same or a division of labor? Immunity. 2009;30(5):626-635.

68. Jacobs JF, Nierkens S, Figdor CG, de Vries IJM, Adema GJ. Regulatory $\mathrm{T}$ cells in melanoma: the final hurdle towards effective immunotherapy? Lancet Oncol. 2012;13(1):e32-e42.

69. Bobo D, Robinson KJ, Islam J, Thurecht KJ, Corrie SR. Nanoparticlebased medicines: a review of FDA-approved materials and clinical trials to date. Pharm Res. 2016;33(10):2373-2387.

70. Wang Z, Zheng Q, Zhang H, et al. Ontak-like human IL-2 fusion toxin. J Immunol Methods. 2017;448:51-58.

71. Telang S, Rasku MA, Clem AL, et al. Phase II trial of the regulatory T cell-depleting agent, denileukin diftitox, in patients with unresectable stage IV melanoma. BMC Cancer. 2011;11(1):515.

72. Attia P, Maker AV, Haworth LR, Rogers-Freezer L, Rosenberg SA. Inability of a fusion protein of IL-2 and diphtheria toxin (Denileukin Diftitox, DAB389IL-2, ONTAK) to eliminate regulatory T lymphocytes in patients with melanoma. J Immunother. 2005;28(6):582-592.

73. Brunet J-F, Denizot F, Luciani M-F, et al. A new member of the immunoglobulin superfamily - CTLA-4. Nature. 1987;328(6127): 267-270.

74. Waterhouse P, Penninger JM, Timms E, et al. Lymphoproliferative disorders with early lethality in mice deficient in Ctla-4. Science. 1995;270(5238):985-985. 
75. Hanson DC, Canniff PC, Primiano MJ, et al. Preclinical in vitro characterization of anti-CTLA4 therapeutic antibody CP-675,206. Am Assoc Cancer Res. 2004;64(7):877.

76. Ribas A, Comin-Anduix B, Economou JS, et al. Intratumoral immune cell infiltrates, FoxP3, and indoleamine 2,3-dioxygenase in patients with melanoma undergoing CTLA4 blockade. Clin Cancer Res. 2009;15(1):390-399.

77. Weide B, Martens A, Wistuba-Hamprecht K, et al. Combined treatment with ipilimumab and intratumoral interleukin-2 in pretreated patients with stage IV melanoma - safety and efficacy in a phase II study. Cancer Immunol Immunother. 2017;66(4):441-449.

78. Brohl AS, Khushalani NI, Eroglu Z, et al. A phase IB study of ipilimumab with peginterferon alfa-2b in patients with unresectable melanoma. J Immunother Cancer. 2016;4(1):85.

79. Hodi FS, O'day SJ, McDermott DF, et al. Improved survival with ipilimumab in patients with metastatic melanoma. $N$ Engl $\mathrm{J} \mathrm{Med}$. 2010;2010(363):711-723.

80. Wolchok JD, Neyns B, Linette G, et al. Ipilimumab monotherapy in patients with pretreated advanced melanoma: a randomised, double-blind, multicentre, phase 2, dose-ranging study. Lancet Oncol. 2010;11(2):155-164.

81. Cho J, Ahn S, Yoo KH, et al. Treatment outcome of PD-1 immune checkpoint inhibitor in Asian metastatic melanoma patients: correlative analysis with PD-L1 immunohistochemistry. Invest New Drugs. 2016;34(6):677-684.

82. Melero I, Grimaldi AM, Perez-Gracia JL, Ascierto PA. Clinical development of immunostimulatory monoclonal antibodies and opportunities for combination. Clin Cancer Res. 2013;19(5):997-1008.

83. Raedler LA. Opdivo (nivolumab): second PD-1 inhibitor receives FDA approval for unresectable or metastatic melanoma. Am Health Drug Benefits. 2015;8(Spec Feature):180-183.

84. Specenier P. Nivolumab in melanoma. Expert Rev Anticancer Ther. 2016;16(12):1247-1261.

85. Franklin C, Livingstone E, Roesch A, Schilling B, Schadendorf D. Immunotherapy in melanoma: recent advances and future directions. Eur J Surg Oncol. 2017;43(3):604-611.

86. Robert C, Schachter J, Long GV, et al. Pembrolizumab versus ipilimumab in advanced melanoma. N Engl J Med. 2015;372(26):2521-2532.

87. Robert C, Ribas A, Wolchok JD, et al. Anti-programmed-deathreceptor-1 treatment with pembrolizumab in ipilimumab-refractory advanced melanoma: a randomised dose-comparison cohort of a phase 1 trial. Lancet. 2014;384(9948):1109-1117.

88. Ribas A, Puzanov I, Dummer R, et al. Pembrolizumab versus investigator-choice chemotherapy for ipilimumab-refractory melanoma (KEYNOTE-002): a randomised, controlled, phase 2 trial. Lancet Oncol. 2015;16(8):908-918.

89. Pol J, Kroemer G, Galluzzi L. First oncolytic virus approved for melanoma immunotherapy. Oncoimmunology. 2015;5(1):e1115641.

90. Hersey P, Gallagher S. Intralesional immunotherapy for melanoma. $J$ Surg Oncol. 2014;109(4):320-326.

91. Mandalà M, Tondini C, Merelli B, Massi D. Rationale for new checkpoint inhibitor combinations in melanoma therapy. Am J Clin Dermatol. 2017;18(5):597-611.

92. Andtbacka RHI, Kaufman H, Daniels GA, et al. CALM study: a phase II study of intratumoral coxsackievirus A21 in patients with stage IIIc and stage IV malignant melanoma. J Clin Oncol. 2013;31(15_Suppl):TPS3128.

93. Panelli MC, Wunderlich J, Jeffries J, et al. Phase 1 study in patients with metastatic melanoma of immunization with dendritic cells presenting epitopes derived from the melanoma-associated antigens MART-1 and gp100. J Immunother. 2000;23(4):487-498.

94. Yuan J, Ku GY, Gallardo HF, et al. Safety and immunogenicity of a human and mouse gp100 DNA vaccine in a phase I trial of patients with melanoma. Cancer Immun. 2009;9(1):5.

95. Schwartzentruber DJ, Lawson DH, Richards JM, et al. gp100 peptide vaccine and interleukin-2 in patients with advanced melanoma. $N$ Engl J Med. 2011;364(22):2119-2127.
96. Kanzler H, Barrat FJ, Hessel EM, Coffman RL. Therapeutic targeting of innate immunity with Toll-like receptor agonists and antagonists. Nat Med. 2007;13(5):552-559.

97. Barton GM, Kagan JC. A cell biological view of Toll-like receptor function: regulation through compartmentalization. Nat Rev Immunol. 2009;9(8):535.

98. Royal RE, Vence LM, Wray T, et al. A toll-like receptor agonist to drive melanoma regression as a vaccination adjuvant or by direct tumor application. J Clin Oncol. 2017;35(15_Suppl):9582.

99. Dudley ME, Yang JC, Sherry R, et al. Adoptive cell therapy for patients with metastatic melanoma: evaluation of intensive myeloablative chemoradiation preparative regimens. J Clin Oncol. 2008;26(32):5233-5239.

100. Chang CH, Pearce EL. Emerging concepts of T cell metabolism as a target of immunotherapy. Nat Immunol. 2016;17(4):364-368.

101. Gattinoni L, Klebanoff CA, Palmer DC, et al. Acquisition of full effector function in vitro paradoxically impairs the in vivo antitumor efficacy of adoptively transferred CD8+ T cells. J Clin Invest. 2005;115(6):1616-1626.

102. Sukumar M, Liu J, Ji Y, et al. Inhibiting glycolytic metabolism enhances CD8+ T cell memory and antitumor function. J Clin Invest. 2013;123(10):4479-4488.

103. Klemen ND, Feingold PL, Goff SL, et al. Metastasectomy following immunotherapy with adoptive cell transfer for patients with advanced melanoma. Ann Surg Oncol. 2017;24(1):135-141.

104. Goff SL, Dudley M, Citrin DE, et al. A randomized, prospective evaluation comparing intensity of lymphodepletion prior to adoptive transfer of tumor infiltrating lymphocytes for patients with metastatic melanoma. J Clin Oncol. 2016;34(15_Suppl):3006.

105. Dudley ME, Wunderlich JR, Yang JC, et al. Adoptive cell transfer therapy following non-myeloablative but lymphodepleting chemotherapy for the treatment of patients with refractory metastatic melanoma. $J$ Clin Oncol. 2005;23(10):2346-2357.

106. Zhang $\mathrm{E}, \mathrm{Xu} \mathrm{H}$. A new insight in chimeric antigen receptor-engineered T cells for cancer immunotherapy. J Hematol Oncol. 2017;10(1):1.

107. Jackson HJ, Rafiq S, Brentjens RJ. Driving CAR T-cells forward. Nat Rev Clin Oncol. 2016;13(6):370-383.

108. Yu S, Li A, Liu Q, et al. Chimeric antigen receptor T cells: a novel therapy for solid tumors. J Hematol Oncol. 2017;10(1):78.

109. Almåsbak H, Aarvak T, Vemuri MC. CAR T cell therapy: a game changer in cancer treatment. J Immunol Res. 2016;2016:5474602.

110. Rupp LJ, Schumann K, Roybal KT, et al. CRISPR/Cas9-mediated PD-1 disruption enhances anti-tumor efficacy of human chimeric antigen receptor T cells. Sci Rep. 2017;7(1):737.

111. Merhavi-Shoham E, Itzhaki O, Markel G, Schachter J, Besser MJ. Adoptive cell therapy for metastatic melanoma. Cancer J. 2017;23(1):48-53.

112. Yvon E, Del Vecchio M, Savoldo B, et al. Immunotherapy of metastatic melanoma using genetically engineered GD2-specific T cells. Clin Cancer Res. 2009;15(18):5852-5860.

113. John LB, Devaud C, Duong CP, et al. Anti-PD-1 antibody therapy potently enhances the eradication of established tumors by genemodified T cells. Clin Cancer Res. 2013;19(20):5636-5646.

114. Galluzzi L, Buque A, Kepp O, Zitvogel L, Kroemer G. Immunological effects of conventional chemotherapy and targeted anticancer agents. Cancer Cell. 2015;28(6):690-714.

115. Siddik ZH. Cisplatin: mode of cytotoxic action and molecular basis of resistance. Oncogene. 2003;22(47):7265-7279.

116. Castle BT, McCubbin S, Prahl LS, Bernens JN, Sept D, Odde DJ. Mechanisms of kinetic stabilization by the drugs paclitaxel and vinblastine. Mol Biol Cell. 2017;28(9):1238-1257.

117. Samlowski WE, Moon J, Witter M, et al. High frequency of brain metastases after adjuvant therapy for high-risk melanoma. Cancer Med. 2017;6(11):2576-2585.

118. Flaherty KT. Targeting metastatic melanoma. Annu Rev Med. 2012;63:171-183.

119. Brose MS, Volpe P, Feldman M, et al. BRAF and RAS mutations in human lung cancer and melanoma. Cancer Res. 2002;62(23):6997-7000. 
120. Ballantyne AD, Garnock-Jones KP. Dabrafenib: first global approval. Drugs. 2013;73(12):1367-1376.

121. Chapman PB, Hauschild A, Robert C, et al. Improved survival with vemurafenib in melanoma with BRAF V600E mutation. $N$ Engl $J$ Med. 2011;364(26):2507-2516.

122. Livingstone E, Zimmer L, Vaubel J, Schadendorf D. BRAF, MEK and KIT inhibitors for melanoma: adverse events and their management. Chin Clin Oncol. 2014;3(3):29.

123. Rizos H, Menzies AM, Pupo GM, et al. BRAF inhibitor resistance mechanisms in metastatic melanoma: spectrum and clinical impact. Clin Cancer Res. 2014;20(7):1965-1977.

124. Pópulo H, Caldas R, Lopes JM, Pardal J, Máximo V, Soares P. Overexpression of pyruvate dehydrogenase kinase supports dichloroacetate as a candidate for cutaneous melanoma therapy. Expert Opin Ther Targets. 2015;19(6):733-745.

125. Abildgaard C, Dahl C, Basse AL, Ma T, Guldberg P. Bioenergetic modulation with dichloroacetate reduces the growth of melanoma cells and potentiates their response to BRAF V600E inhibition. $J$ Transl Med. 2014;12(1):247.

126. Curtin JA, Fridlyand J, Kageshita T, et al. Distinct sets of genetic alterations in melanoma. $N$ Engl J Med. 2005;353(20):2135-2147.

127. Davies H, Bignell GR, Cox C, Stephens P. Mutations of the BRAF gene in human cancer. Nature. 2002;417(6892):949.

128. Gencler B, Gonul M. Cutaneous side effects of BRAF inhibitors in advanced melanoma: review of the literature. Dermatol Res Pract. 2016;2016:5361569.

129. Flaherty KT, Robert C, Hersey P, et al. Improved survival with MEK inhibition in BRAF-mutated melanoma. $N$ Engl $J$ Med. 2012;367(2):107-114.

130. Ascierto PA, Schadendorf D, Berking C, et al. MEK162 for patients with advanced melanoma harbouring NRAS or Val600 BRAF mutations: a non-randomised, open-label phase 2 study. Lancet Oncol. 2013;14(3):249-256.

131. Wright CJ, McCormack PL. Trametinib: first global approval. Drugs. 2013;73(11):1245-1254.

132. Flaherty KT, Infante JR, Daud A, et al. Combined BRAF and MEK inhibition in melanoma with BRAF V600 mutations. $N$ Engl J Med. 2012;367(18):1694-1703.

133. Niezgoda A, Niezgoda P, Czajkowski R. Novel approaches to treatment of advanced melanoma: a review on targeted therapy and immunotherapy. Biomed Res Int. 2015;2015:851387.

134. Hoeflich KP, Merchant M, Orr C, et al. Intermittent administration of MEK inhibitor GDC-0973 plus PI3K inhibitor GDC-0941 triggers robust apoptosis and tumor growth inhibition. Cancer Res. 2012;72(1): 210-219.

135. Larkin J, Ascierto PA, Dréno B, et al. Combined vemurafenib and cobimetinib in BRAF-mutated melanoma. $N$ Engl J Med. 2014;371(20): 1867-1876.

136. Willmore-Payne C, Holden JA, Tripp S, Layfield LJ. Human malignant melanoma: detection of BRAF- and c-kit-activating mutations by highresolution amplicon melting analysis. Hum Pathol. 2005;36(5):486-493.

137. Curtin JA, Busam K, Pinkel D, Bastian BC. Somatic activation of KIT in distinct subtypes of melanoma. J Clin Oncol. 2006;24(26):4340-4346.

138. Carlino MS, Todd JR, Rizos H. Resistance to c-kit inhibitors in melanoma: insights for future therapies. Oncoscience. 2014;1(6):423-426.

139. Heinrich MC, Corless CL, Demetri GD, et al. Kinase mutations and imatinib response in patients with metastatic gastrointestinal stromal tumor. J Clin Oncol. 2003;21(23):4342-4349.

140. Hodi FS, Corless CL, Giobbie-Hurder A, et al. Imatinib for melanomas harboring mutationally activated or amplified KIT arising on mucosal, acral, and chronically sun-damaged skin. J Clin Oncol. 2013;31(26):3182-3190.

141. Hodi FS, Friedlander P, Corless CL, et al. Major response to imatinib mesylate in KIT-mutated melanoma. J Clin Oncol. 2008;26(12):2046-2051.
142. Guo J, Si L, Kong Y, et al. Phase II, open-label, single-arm trial of imatinib mesylate in patients with metastatic melanoma harboring c-Kit mutation or amplification. J Clin Oncol. 2011;29(21):2904-2909.

143. Tas F, Duranyildiz D, Oguz H, Camlica H, Yasasever V, Topuz E. Circulating serum levels of angiogenic factors and vascular endothelial growth factor receptors 1 and 2 in melanoma patients. Melanoma Res. 2006;16(5):405-411.

144. Mehnert JM, McCarthy MM, Jilaveanu L, et al. Quantitative expression of VEGF, VEGF-R1, VEGF-R2, and VEGF-R3 in melanoma tissue microarrays. Hum Pathol. 2010;41(3):375-384.

145. Folkman J, Klagsbrun M. Angiogenic factors. Science. 1987;235(4787):442-448.

146. Kim KJ, Li B, Winer J, et al. Inhibition of vascular endothelial growth factor-induced angiogenesis suppresses tumour growth in vivo. Nature. 1993;362(6423):841-844.

147. Von Moos R, Seifert B, Simcock M, et al. First-line temozolomide combined with bevacizumab in metastatic melanoma: a multicentre phase II trial (SAKK 50/07). Ann Oncol. 2011;23(2):531-536.

148. Pópulo H, Lopes JM, Soares P. The mTOR signalling pathway in human cancer. Int J Mol Sci. 2012;13(2):1886-1918.

149. Populo H, Soares P, Faustino A, et al. mTOR pathway activation in cutaneous melanoma is associated with poorer prognosis characteristics. Pigment Cell Melanoma Res. 2011;24(1):254-257.

150. Li X, Wu D, Shen J, Zhou M, Lu Y. Rapamycin induces autophagy in the melanoma cell line M14 via regulation of the expression levels of Bcl-2 and Bax. Oncol Lett. 2013;5(1):167-172.

151. Kwong L, Davies M. Targeted therapy for melanoma: rational combinatorial approaches. Oncogene. 2014;33(1):1-19.

152. Populo H, Tavares S, Faustino A, Nunes JB, Lopes JM, Soares P. GNAQ and BRAF mutations show differential activation of the mTOR pathway in human transformed cells. PeerJ. 2013;1:e104.

153. Atefi M, von Euw E, Attar N, et al. Reversing melanoma crossresistance to BRAF and MEK inhibitors by co-targeting the AKT/ mTOR pathway. PLoS One. 2011;6(12):e28973.

154. Deng W, Gopal YN, Scott A, Chen G, Woodman SE, Davies MA. Role and therapeutic potential of PI3K-mTOR signaling in de novo resistance to BRAF inhibition. Pigment Cell Melanoma Res. 2012;25(2):248-258.

155. Gotwals P, Cameron S, Cipolletta D, et al. Prospects for combining targeted and conventional cancer therapy with immunotherapy. Nat Rev Cancer. 2017;17(5):286-301.

156. Soura E, Eliades PJ, Shannon K, Stratigos AJ, Tsao H. Hereditary melanoma: update on syndromes and management: genetics of familial atypical multiple mole melanoma syndrome. J Am Acad Dermatol. 2016;74(3):395-407.

157. Bennett DC. Human melanocyte senescence and melanoma susceptibility genes. Oncogene. 2003;22(20):3063-3069.

158. Goldstein A, Chidambaram A, Halpern A, et al. Rarity of CDK4 germline mutations in familial melanoma. Melanoma Res. 2002;12(1):51-55

159. O'leary B, Finn RS, Turner NC. Treating cancer with selective CDK4/6 inhibitors. Nat Rev Clin Oncol. 2016;13(7):417-430.

160. Ranade K, Hussussian CJ, Sikorski RS, et al. Mutations associated with familial melanoma impair p16INK4 function. Nat Genet. 1995;10(1):114-116.

161. Prével C, Pellerano M, González-Vera JA, et al. Fluorescent peptide biosensor for monitoring CDK4/cyclin D kinase activity in melanoma cell extracts, mouse xenografts and skin biopsies. Biosens Bioelectron. 2016;85:371-380.

162. Yadav V, Burke TF, Huber L, et al. The CDK4/6 inhibitor LY2835219 overcomes vemurafenib resistance resulting from MAPK reactivation and cyclin D1 upregulation. Mol Cancer Ther. 2014;13(10):2253-2263.

163. Prickett TD, Agrawal NS, Wei X, et al. Analysis of the tyrosine kinome in melanoma reveals recurrent mutations in ERBB4. Nat Genet. 2009;41(10):1127-1132. 
ImmunoTargets and Therapy

\section{Publish your work in this journal}

ImmunoTargets and Therapy is an international, peer-reviewed open access journal focusing on the immunological basis of diseases, potential targets for immune based therapy and treatment protocols employed to improve patient management

Basic immunology and physiology of the immune system in health, and disease will be also covered. In addition, the journal will focus on the impact of manage-

ment programs and new therapeutic agents and protocols on patient perspectives such as quality of life, adherence and satisfaction. The manuscript management system is completely online and includes a very quick and fair peer-review system, which is all easy to use. Visit http://www.dovepress.com/testimonials.php to read real quotes from published authors.

Submit your manuscript here: http://www.dovepress.com/immunotargets-and-therapy-journal 